\title{
The expression and function of Toll-like receptors 3 and 9 in human colon carcinoma
}

\author{
KEIICHIRO NOJIRI ${ }^{1}$, KAZUSHI SUGIMOTO $^{1}$, KATSUYA SHIRAKI $^{1}$, MASAHIKO TAMEDA $^{1}$, \\ YUUJI INAGAKI ${ }^{1}$, SATOKO KUSAGAWA ${ }^{1}$, SUGURU OGURA ${ }^{1}$, JUNICHIRO TANAKA $^{1}$, \\ MISAO YONEDA $^{1}$, NORIHIKO YAMAMOTO ${ }^{1}$, HIROSHI OKANO ${ }^{1}$, YOSHIYUKI TAKEI ${ }^{1}$, \\ MASAAKI ITO $^{1}$, CHIKA KASAI $^{2}$, HIDEKAZU INOUE ${ }^{2}$ and KOUJIRO TAKASE ${ }^{2}$ \\ Departments of ${ }^{1}$ Internal Medicine and ${ }^{2}$ Molecular Diagnosis, Mie Graduate University \\ School of Medicine, Tsu, Mie 514-8507, Japan
}

Received September 18, 2012; Accepted October 12, 2012

DOI: $10.3892 /$ or.2013.2322

\begin{abstract}
Toll-like receptors (TLRs) are pattern-recognition receptors that are important in immune signaling. TLR recognition of various viral componentsincluding double-stranded RNA (TLR3) and unmethylated CpG-DNA (TLR9) plays a crucial role in cell survival. However, TLR expression and function in colon carcinoma cells are not well clarified. We investigated the expression of TLR3 and TLR9 in colon carcinoma cells using immunohistochemical methods. The function of TLR3 and TLR9 signaling in carcinoma cell lines was studied by direct cell stimulation with, or by cell transfection of, polyinosinicpolycytidylic acid (Poly I:C), a synthetic form of dsRNA, and by cell stimulation with $\mathrm{CpG}$-oligodeoxynucleotides (ODNs), respectively. Positive TLR3 and TLR9 immunohistochemical staining was observed in 91 and $86 \%$ of human hepatocellular carcinoma (HCC) tissues, respectively. Cell surface stimulation of TLR3 with Poly I:C did not affect cell viability but it did activate NF- $\mathrm{KB}$ activity. By contrast, stimulation of intracellular TLRs with transfected Poly I:C significantly induced apoptosis. Cell surface stimulation of TLR9 with CpG-ODNs promoted cell proliferation, and, furthermore, these CpG-ODN TLR9 agonists reduced the cytotoxicity of the anticancer drug adriamycin. Cell surface expression of TLR3 and TLR9 in colon carcinoma cells plays an important role in cell survival. In addition, the proapoptotic activity of intracellularly expressed TLR3 may provide the possibility of using TLR3 agonists as novel clinical cytotoxic agents against colon carcinoma cells.
\end{abstract}

\section{Introduction}

Toll-like receptors (TLRs) play a critical role in innate immunity against microbial pathogens, as well as in the subsequent

Correspondence to: Dr Katsuya Shiraki, Department of Internal Medicine, Mie Graduate University School of Medicine, 2-174 Edobashi, Tsu, Mie 514-8507, Japan

E-mail: katsuyas@clin.medic.mie-u.ac.jp

Key words: Toll like receptor, apoptosis, colon cancer induction of adaptive immune responses (1-3). These receptors are the major pattern-recognition transducers in response to microbial intruders such as bacteria, protozoa, fungi or viruses (4). Stimulation of TLRs induces a range of innate and adaptive immune responses through cytokines, interferons, chemokines and cell surface molecules, in addition to increasing the effector functions of TLR-expressing cells.

TLR2 and TLR4 play a key role in the recognition of various bacteria. Viral glycoproteins are recognized by TLRs 2 and 4, virus-related double-stranded RNA (dsRNA) by TLR3 and single-stranded RNA (ssRNA) by TLRs 7 and 8. TLR9 recognizes specific oligodeoxynucleotide (ODN) sequences that consist of unmethylated $\mathrm{CpG}-\mathrm{ODNs}$, which are frequently present in bacterial and viral DNA (5).

TLRs are broadly distributed in various cells of the immune system, including polymorphonuclear phagocytes, monocytes, dendritic cells and natural killer cells, as well as in some epithelial and endothelial cells $(6,7)$. The specific subcellular localization of TLRs remains unclear. TLRs 1,2, 4, 5 and 6 are present in the plasma membrane. TLRs 3, 7, 8 and 9 are mainly present in endosomes and are likely to signal from acidic endosomes (8).

Signaling pathways activated by specific TLRs are largely dictated by the adaptor proteins that are recruited to the intracellular domain of the TLR. MyD88 is involved in the majority of TLR pathways, except for TLRs 3 and 8. TLR3 signaling depends solely on its binding to the adaptor protein termed the Toll/Interleukin-1 receptor domain-containing adaptorinducing IFN- $\beta$ (TRIF) adaptor protein. Binding of TRIF to TLR3 leads to the activation of NF- $\kappa \mathrm{B}$ and IRF3 transcription factors, thereby inducing the antiviral interferon response $(9,10)$.

In humans, TLR9 is expressed in B-lymphocytes, monocytes and plasmacytoid dendritic cells. TLR9 recognizes specific oligodeoxynucleotide (ODN) sequences consisting of unmethylated $\mathrm{CpG}-\mathrm{ODNs}$, which are frequently present in bacterial and viral DNA (5).

TLRs have recently been found to be expressed in various normal epithelial and cancer cells (11-18). Of these cells, gastrointestinal epithelial cells in particular are constantly exposed to external microbial pathogens or viruses. Therefore, TLRs play a critical role not only in immune defense but also in other biological functions. 
In addition, we have previously reported that human hepatocellular carcinoma (HCC) cells express TLR3 and TLR9 and that these receptors function mainly in cell survival and in anti-apoptotic pathways $(15,16)$. Previous reports indicated that colorectal cancer cells express TLR2, TLR3, TLR4, TLR5 and TLR9. These findings indicated that TLRs might play an important role also in colorectal cancer cells.

Recent reports have suggested that the neoplastic process may sabotage TLR signaling pathways to favor cancer progression. TLRs on tumor cells facilitate their evasion from immune surveillance via suppression of T-cell proliferation and natural killer cell activity. These studies suggest that TLR signaling in tumor cells is associated with the progression of cancer $(12,14)$. However, the functions of TLRs in colon carcinoma cells are not well understood. We therefore investigated the expression of TLR3 and TLR9 in colon carcinoma cell lines and in primary human normal and carcinogenic colon tissues, and attempted to clarify the function of TLR3 and TLR9 in colon carcinoma cells.

\section{Materials and methods}

Cells and HCC tissues. The colon adenocarcinoma cells Colo320 and SW480 were purchased from the American Type Culture Collection (Rockville, MD, USA). All cells were cultured in DMEM at $37^{\circ} \mathrm{C}$, supplemented with $1 \%$ penicillin/streptomycin (Gibco BRL, Grand Island, NY, USA) and $10 \%$ heat-inactivated fetal calf serum (Gibco BRL).

A total of 42 colon carcinoma tissues ( 9 non-tumor tissues, and 8 tissues with metastasis from colon carcinoma tissues) were obtained from tissue array slides (SuperBioChips Laboratories, Seoul, Korea). We obtained informed consent from all patients prior to the subsequent use of their resected tissues. Resected tissues were frozen immediately at $-80^{\circ} \mathrm{C}$ or were fixed in $10 \%$ formalin.

Reagents. Polyinosinic-polycytidylic acid (Poly I:C), which was used as a human TLR3 ligand, was obtained from Sigma (St. Louis, MO, USA), and Lipofectamine LTX (Lipo) was obtained from Invitrogen (Carlsbad, CA, USA). The type C CpG oligonucleotide (ODN M362: 5 '-tcg tcg tcg ttc gaa cga cgt tga $\left.\mathrm{t}-3^{\prime}\right)$, which was used as a human TLR9 ligand, and the control, non-stimulatory oligonucleotide ODN M362 (ODN M362 control: $5^{\prime}-\operatorname{tgc} \operatorname{tgc} \operatorname{tgc} \operatorname{tg}$ caa gca gct tga $\left.\mathrm{t}-3^{\prime}\right)$, were purchased from InvivoGen (San Diego, CA, USA). Adriamycin (ADM) was purchased from Wako (Osaka, Japan).

Immunohistochemical staining. Immunohistochemical staining of TLR3 and TLR9 expression in colon carcinoma and non-colon carcinoma tissues was performed using the labeled streptavidin-biotin method. Deparaffinized sections were heated for $5 \mathrm{~min}$ at $120^{\circ} \mathrm{C}$ in a pressure cooker to reactivate the antigen. Sections were blocked and incubated with anti-TLR3 or 9 antibodies (Santa Cruz Biotechnology, Santa Cruz, CA, USA), overnight at $4^{\circ} \mathrm{C}$. The sections were then incubated with a second biotinylated antibody, followed by an avidin-biotin-peroxidase complex. The sections were then developed in a substrate solution of $0.01 \%$ 3,3'-diaminobenzidene-hydrogen peroxidase and counterstained with $10 \%$ hematoxylin.
Table I. Expression of TLR3 in colon carcinoma and non-tumor tissues.

\begin{tabular}{|c|c|c|c|}
\hline \multirow[b]{2}{*}{ Histology } & \multicolumn{3}{|c|}{ Staining } \\
\hline & $\begin{array}{l}\text { Absent or } \\
\text { weak (\%) }\end{array}$ & $\begin{array}{c}\text { Moderate } \\
(\%)\end{array}$ & $\begin{array}{l}\text { Strong } \\
(\%)\end{array}$ \\
\hline Non-tumor tissue & $1(11.1)$ & $8(88.9)$ & (0) \\
\hline Colon carcinoma & & & \\
\hline Poorly differentiated & $1(33.3)$ & $2(66.7)$ & (0) \\
\hline Moderately differentiated & $4 \quad(6.4)$ & $36(57.1)$ & $23(36.5)$ \\
\hline Well differentiated & $3(12.0)$ & $15(60.0)$ & $7(28.0)$ \\
\hline
\end{tabular}

\section{TLR3}

\section{SW480 Colo320}

Figure 1. TLR-3 expression in colon carcinoma cell lines. TLR3 expression in the SW480 and Colo320 colon carcinoma cell lines was assessed by western blot analysis.

Detection of TLR 3 and 9 protein expression by immunoblotting. The expression of TLRs 3 and 9, and that of the loading control $\alpha$-tubulin, in colon adenocarcinoma cell lines (Colo320, SW480) was analyzed by immunoblotting. Briefly, after incubation of the cells on 6-well plates (Nunc ${ }^{\mathrm{TM}}$ Brand Products, Denmark) for $48 \mathrm{~h}$, the cells were washed twice with phosphate-buffered saline (PBS) and were then lysed by the addition of SDS sample buffer $(50 \mathrm{mmol} / \mathrm{l}$ Tris-HCl, pH 6.8, 2.5\% SDS, 5\% glycerol, $5 \%$ 2-mercaptoethanol and $0.01 \%$ bromophenol blue). Equal amounts of extracted proteins were separated by SDS-PAGE and were then transferred to PVDF membranes (Millipore, Billerica, MA, USA). Blots were blocked by incubation in Tris- $\mathrm{HCl}(\mathrm{pH} 7.5)$ containing 5\% milk and $0.1 \%$ Tween-20 for $30 \mathrm{~min}$ at room temperature, and were probed overnight at $4^{\circ} \mathrm{C}$ with the primary antibodies. The following primary antibodies were used: anti-TLR3 or TLR9 monoclonal antibody (Imgenex, San Diego, CA, USA) and anti- $\alpha$-tubulin monoclonal antibody (Oncogene Research Products, San Diego, CA, USA). The antibodies were diluted in 5\% milk or in BSA in Tris- $\mathrm{HCl}(\mathrm{pH} 7.5)$ containing $0.1 \%$ Tween-20. The immunoblots were then probed with horseradish peroxidase-conjugated anti-mouse immunoglobulin $\mathrm{G}(\mathrm{IgG})$ (diluted 1:1000 in $1 \%$ milk or in BSA in Tris-HCl, pH 7.5) (Amersham Biosciences, Buckinghamshire, UK) After the final wash, signals were detected using an ECL kit (Amersham Pharmacia Biotech).

Detection of cell viability and apoptosis assay. The colon carcinoma cell lines were seeded at a density of $1.0 \times 10^{4}$ cells/ well in 96-well flat-bottom microtiter plates (Corning Glass Works, Corning, NY, USA) and were incubated at $37^{\circ} \mathrm{C}$ in $5 \%$ $\mathrm{CO}_{2}$. After incubation for $24 \mathrm{~h}$, reagents were added, and the plates were incubated for a further $48 \mathrm{~h}$. To assess the viability of the colon carcinoma cells, a 3-(4,5-dimethylthiazol-2-yl)2,5-diphenyl tetrazolium bromide (MTT) assay was performed 

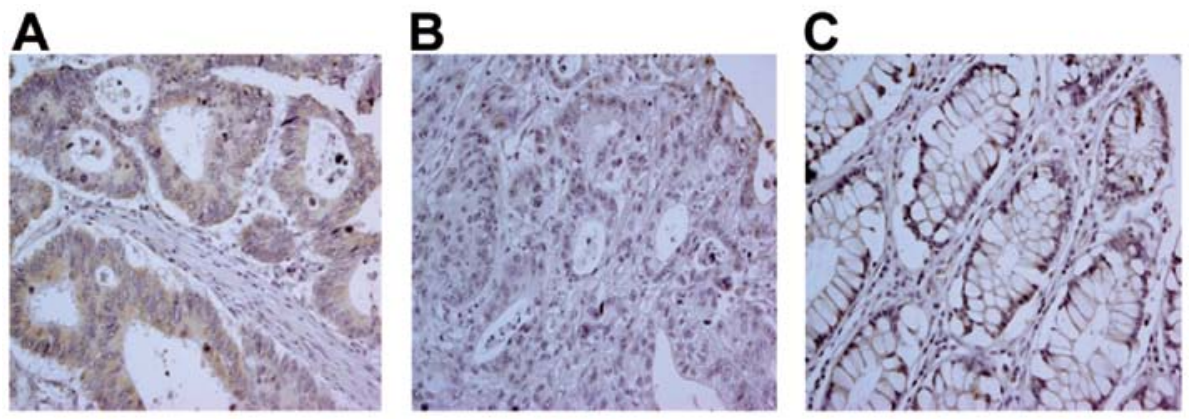

Figure 2. Immunohistochemical analysis of TLR3 expression in human colon tissues. A representative human colon carcinoma (A) and a non-colon carcinoma (B) tissue specimen were immunohistochemically stained using an anti-TLR3 antibody. A control, human normal sigmoid colon specimen (C) was immunohistochemically stained using an isotype matched mouse IgG. Staining was carried out using a streptavidin-biotin labeling method. TLR3 staining was observed in the cytoplasm as well as in the cell membrane (original magnification, $\mathrm{x} 400$ ).
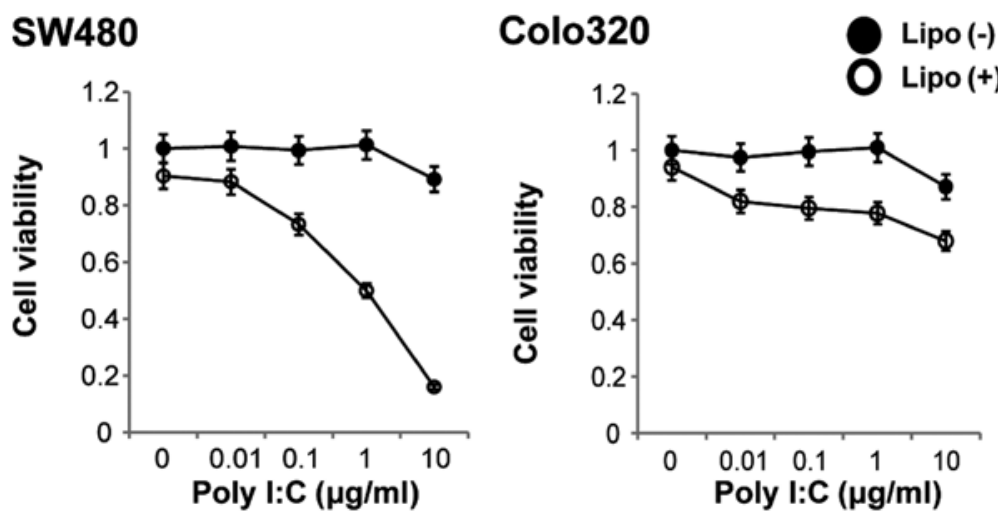

Figure 3. Effect of exogenous and endogenous Poly I:C on colon carcinoma cell viability. The indicated colon carcinoma cell lines were incubated without or with different concentrations of Poly I:C in the absence [Lipo (-)] or presence [(Lipo (+)] of $2.5 \mu \mathrm{l} / \mathrm{ml}$ Lipofectamine LTX for $48 \mathrm{~h}$ following which cell viability was assessed using the MTT assay. Cell viability in the absence of treatment was set at 1 . Data shown are the means \pm SD of six independent experiments.

using the Cell Titer 96-assay kit (Promega, Madison, WI, USA) according to the manufacturer's instructions. For analysis of apoptosis, a total of $2 \times 10^{4}$ SW480 cells were cultured in a chamber slide for $24 \mathrm{~h}$ followed by no addition, or by the addition of $1 \mu \mathrm{g} / \mathrm{ml}$ of either Poly I:C or Lipo, or of $1 \mu \mathrm{g} / \mathrm{ml}$ Poly I:C plus Lipo. After incubation for $24 \mathrm{~h}$, cell nuclei were stained with 4'6,-diamidino-2-phenylindole (DAPI; Sigma) and the cells were analyzed under a fluorescent microscope.

$N F-\kappa B$ activity assays. The NF- $\kappa \mathrm{B}$ activity assay was performed using the Dual-Glo ${ }^{\mathrm{TM}}$ Luciferase Assay System (Promega) and the pGL4.32 (luc2P/NF- $\kappa \mathrm{B}-\mathrm{RE} /$ Hygro) Vector (Promega) according to the manufacturer's instructions.

\section{Results}

TLR3 is expressed in colon carcinoma cell lines and colon tissues. As shown in Fig. 1, TLR3 expression was detected by western blotting in both of the colon carcinoma cell lines tested. TLR3 expression in primary human colon tissue was then investigated by immunohistochemical staining of both non-colon carcinoma and colon carcinoma lesions (Fig. 2, representative staining). While there was a clear positive TLR3 signal in 91/100 colon carcinoma cases (91\%), no major differences in TLR3 expression were observed between different histological tumor grades (Table I). TLR3 staining
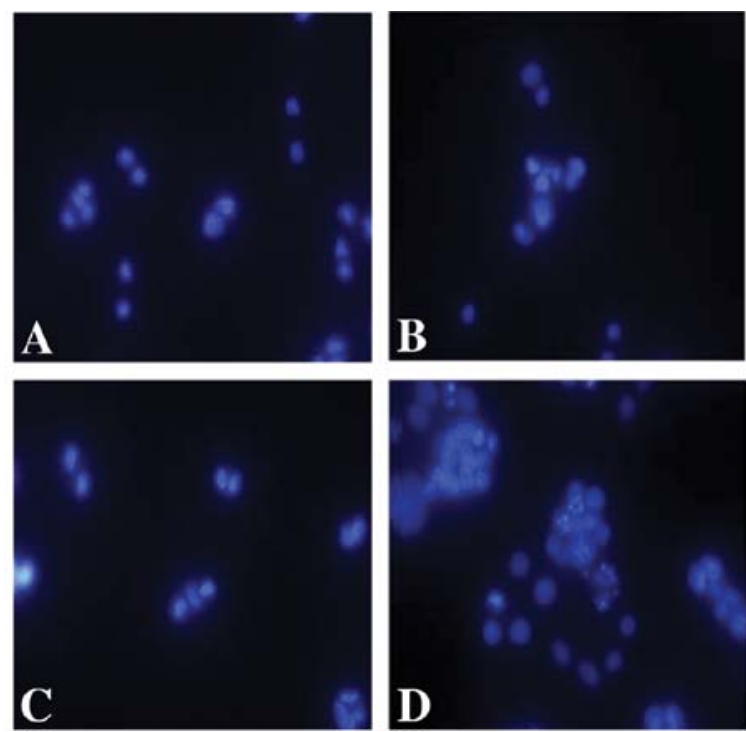

Figure 4. Effect of transfected Poly I:C on apoptosis of SW480 cells. The cells were incubated with $1 \mu \mathrm{g} / \mathrm{ml}$ Poly I:C, $2.5 \mu \mathrm{l} / \mathrm{ml}$ Lipofectamine LTX or $1 \mu \mathrm{g} / \mathrm{ml}$ Poly I:C $+2.5 \mu \mathrm{l} / \mathrm{ml}$ Lipo for $24 \mathrm{~h}$. Cell nuclei were then visualized by DAPI staining. (A) Control; (B) Poly I:C; (C) LTX; (D) Transfected Poly I:C.

was detected not only in the cytoplasm, but also in the cell membrane. Few differences were noted in the TLR3 staining patterns between non-tumor and tumor tissues. 


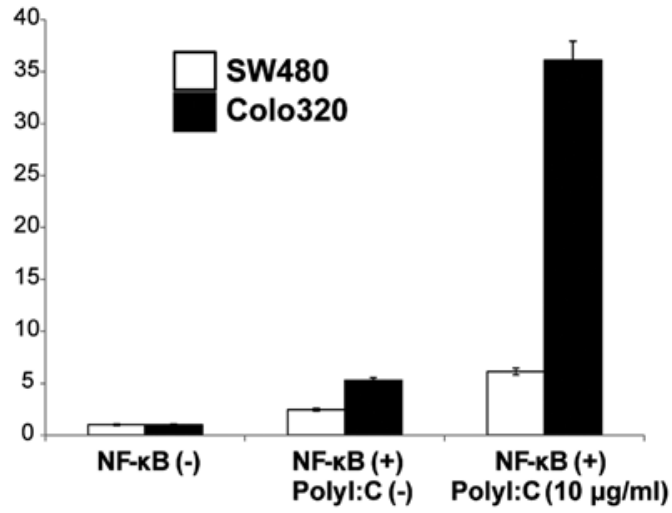

Figure 5. Effect of incubation of colon carcinoma cells with Poly I:C on NF-кB activation. Colon carcinoma cells were either not transfected [NF- $\mathrm{kB}(-)$, control] or were transfected $[\mathrm{NF}-\mathrm{\kappa B}(+)]$ with the $\mathrm{NF}-\kappa \mathrm{B}-$ luciferase reporter. Transfected cells were either not stimulated [Poly I:C(-)], or were stimulated

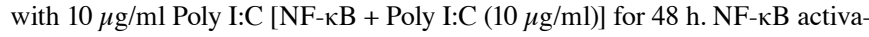
tion was assessed using a Luciferase assay. Data shown are the means $\pm \mathrm{SE}$ of three independent experiments.

\section{TLR9}

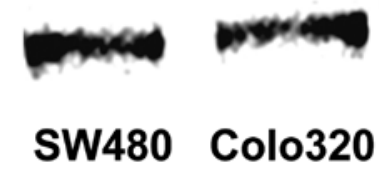

Figure 6. TLR-9 expression in colon carcinoma cell lines. TLR9 expression in SW480 and Colo320 cell lines was assessed by western blot analysis.

Transfected Poly I:C-induced apoptosis in colon carcinoma cells. Cellular TLR3 is stimulated by Poly I:C. We therefore next investigated the cytotoxicity of non-transfected or of transfected Poly I:C for these colon carcinoma cells. Stimulation of both cell lines with various concentrations of non-transfected Poly I:C for $48 \mathrm{~h}$ resulted in no change in cell viability, whereas stimulation of the cells with transfected Poly I:C for $48 \mathrm{~h}$ resulted in a decrease in cell viability in a dose-dependent manner in the SW480 cell line (Fig. 3). We then determined whether transfection of Poly I:C induced apoptosis in these SW480 cells by staining the nuclei with DAPI. Whereas apoptosis was not induced in the cells following treatment with non-transfected Poly I:C, typical apoptotic features of the nuclei were observed in the colon carcinoma cells that were treated with transfected Poly I:C (Fig. 4).
Table II. Expression of TLR9 in colon carcinoma and non-tumor tissues.

\begin{tabular}{|c|c|c|c|}
\hline \multirow[b]{2}{*}{ Histology } & \multicolumn{3}{|c|}{ Staining } \\
\hline & $\begin{array}{l}\text { Absent or } \\
\text { weak }(\%)\end{array}$ & $\begin{array}{c}\text { Moderate } \\
(\%)\end{array}$ & $\begin{array}{c}\text { Strong } \\
(\%)\end{array}$ \\
\hline Non-tumor tissue & $1(11.1)$ & $8(88.9)$ & $(0)$ \\
\hline \multicolumn{4}{|l|}{ Colon carcinoma } \\
\hline Poorly differentiated & $3(100)$ & $0 \quad(0)$ & $0 \quad(0)$ \\
\hline Moderately differentiated & $7(10.8)$ & $35(53.8)$ & $23(35.4)$ \\
\hline Well differentiated & $3(13.0)$ & $12(52.2)$ & $8(34.8)$ \\
\hline
\end{tabular}

Poly I:C-induced $N F-\kappa B$ activation. Since TLR3 signaling is known to modulate NF- $\kappa \mathrm{B}$ signaling pathways we further examined if activation of TLR3 by Poly I:C stimulation mediated induction of NF- $\kappa \mathrm{B}$ in the two cell lines. NF- $\kappa \mathrm{B}$ activity following cell surface stimulation with Poly I:C was assayed using a luciferase reporter assay and was compared to that in the absence of stimulation. Stimulation of the cells with Poly I:C resulted in increased $\mathrm{NF}-\kappa \mathrm{B}$ activity in both the SW480 and the Colo320 cell lines compared to the non-stimulated cells (Fig. 5). These results indicated that cell surface stimulation with Poly I:C activates the NF- $\mathrm{B}$ signaling pathway.

TLR9 is expressed in colon carcinoma cell lines and colon tissues. As shown in Fig. 6, TLR9 protein expression was detected in both colon carcinoma cell lines by western blotting. TLR9 expression in colon tissue was further investigated by immunohistochemical staining of both non-colon carcinoma tissue and colon carcinoma lesions (Fig. 7, representative staining). While 86/100 colon carcinoma cases (86\%) displayed a clear positive TLR9 signal, no major differences in TLR9 signals were observed between different histological grades of the tumors (Table II). TLR9 staining was detected not only in the cytoplasm, but also in the cell membrane.

CpG-ODNs affect cell proliferation. In order to determine the biological significance of the signaling that occurs via the cell surface TLR9 in colon carcinoma cells, we investigated the cytotoxicity of treatment of the two colon carcinoma cell lines with the TLR9 ligand CpG-ODNs. As shown in Fig. 8,
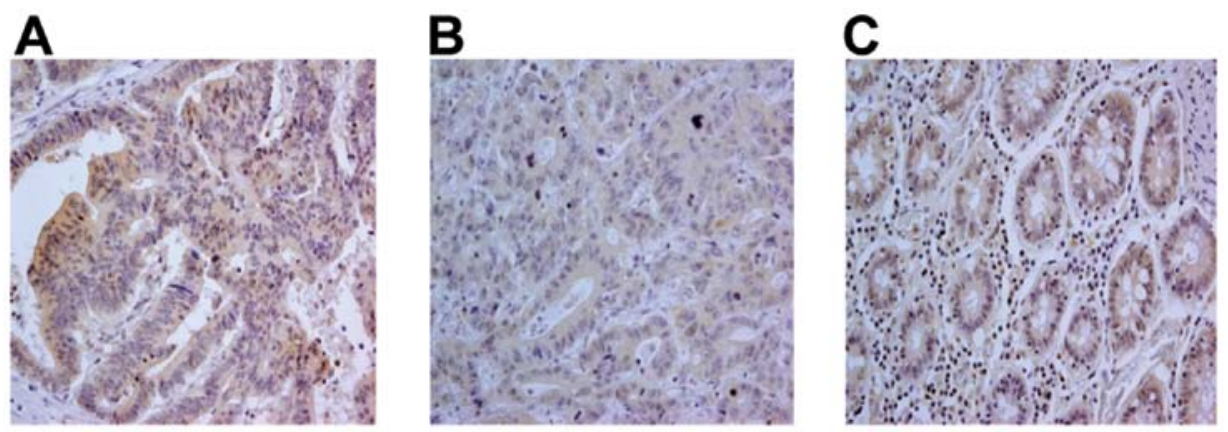

Figure 7. Immunohistochemical analysis of TLR9 expression in human colon tissue. A representative human colon carcinoma (A) and a non-colon carcinoma (B) tissue specimen were immunohistochemically stained using an anti-TLR9 antibody. A control, human normal sigmoid colon specimen (C) was immunohistochemically stained using an isotype matched mouse IgG. Staining was carried out using a streptavidin-biotin labeling method. TLR9 staining was observed in the cytoplasm as well as in the cell membrane (original magnification, $\mathrm{x} 400$ ). 


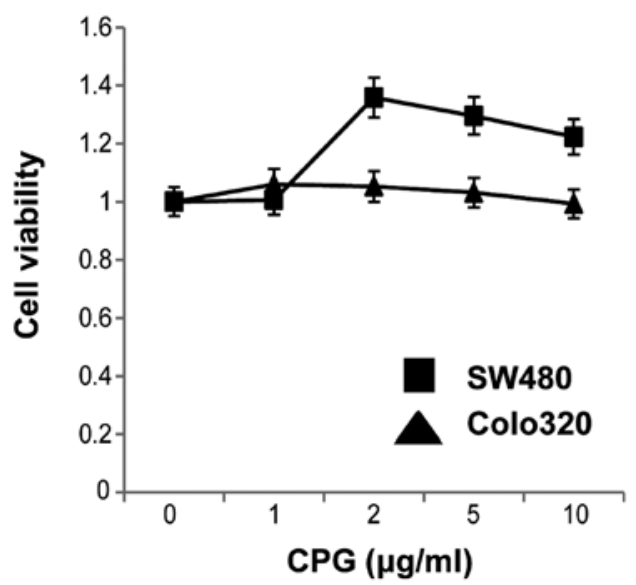

Figure 8. Effect of exogenous $\mathrm{CpG}$ on colon carcinoma cell viability. The indicated colon carcinoma cells were incubated with various concentrations of $\mathrm{CpG}$ for $48 \mathrm{~h}$ following which cell viability was assessed using the MTT assay. Cell viability in the absence of treatment was set at 1 . Data shown are the means \pm SD of six independent experiments.

stimulation of the two cell lines with CpG-ODNs for $48 \mathrm{~h}$ increased the viability of SW480 cells. This result suggested that cell surface stimulation with $\mathrm{CpG-ODNs} \mathrm{might} \mathrm{affect} \mathrm{cell}$ proliferation and survival in colon carcinoma cells.

$C p G-O D N s$ reduce the cytotoxicity of ADM. We next examined possible interactions between the effect of CpG-ODNs and that of the anticancer reagent, adriamycin (ADM), on the viability of the colon carcinoma cell line Colo320. Cell surface stimulation of Colo320 cells with a combination of $1 \mu \mathrm{M}$ $\mathrm{CpG}-\mathrm{ODNs}$ and $2 \mu \mathrm{g} / \mathrm{ml} \mathrm{ADM}$ for $48 \mathrm{~h}$ resulted in an increase in cell viability of $\sim 23 \%$ compared to ADM treatment alone. Furthermore, cell surface stimulation with a combination of $1 \mu \mathrm{M}$ CpG-ODNs and $5 \mu \mathrm{g} / \mathrm{ml}$ ADM for $48 \mathrm{~h}$ resulted in an increase in cell viability of $\sim 12 \%$ compared to stimulation with ADM alone (Fig. 9). These results suggest that CpG-ODNs might contribute to a reduction in the cytotoxicity of ADM.

$C p G-O D N s$ activate the $N F-\kappa B$ signaling pathway. Since TLR9 signaling is known to modulate NF- $\kappa \mathrm{B}$ signaling

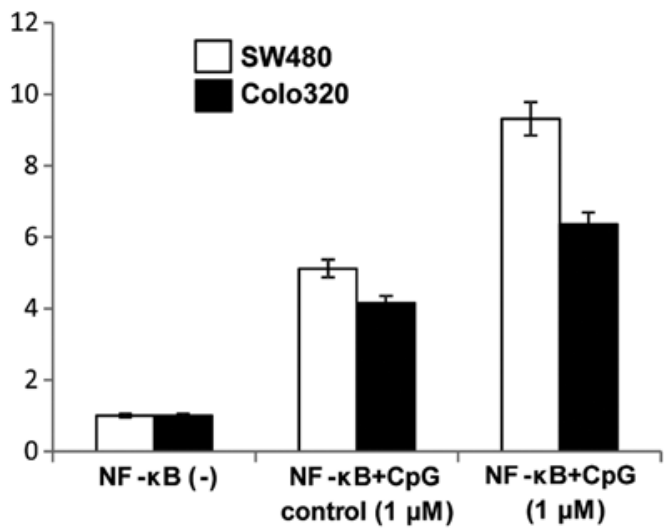

Figure 10. Effect of $\mathrm{CpG}$ on $\mathrm{NF}-\kappa \mathrm{B}$ activation in colon carcinoma cells. Colon carcinoma cells were either not transfected $[\mathrm{NF}-\kappa \mathrm{B}(-)$, control] or were trans-

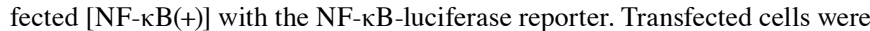
either stimulated with $1 \mu \mathrm{M}$ of a control CpG ODN M362 [NF- $\kappa \mathrm{B}(+) \mathrm{CpG}$ control], or with $1 \mu \mathrm{M}$ of the TLR9 CpG ODN ligand [NF- $\kappa \mathrm{B}(+) \mathrm{CpG}(1 \mu \mathrm{M})]$ for $48 \mathrm{~h}$. NF- $\kappa \mathrm{B}$ activation was assessed using a Luciferase assay. Data shown are the means $\pm \mathrm{SE}$ of three independent experiments.

pathways we further examined if CpG-ODN stimulation of TLR9 mediated induction of $N F-\kappa B$ activity. Induction of $\mathrm{NF}-\kappa \mathrm{B}$ activity following cell surface stimulation with $1 \mu \mathrm{M}$ $\mathrm{CpG}-\mathrm{ODNs}$ was assayed using a luciferase reporter assay and was compared to the NF- $\kappa \mathrm{B}$ activity of non-simulated cells. NF- $\kappa \mathrm{B}$ activity of both colon carcinoma cell lines was increased by treatment with $1 \mu \mathrm{M} \mathrm{CpG-ODNs} \mathrm{(Fig.} \mathrm{10).}$

\section{Discussion}

TLRs are essential for immune defense against microbes and viruses. TLR agonists enhance tumor immunotherapy by stimulating TLR signaling in immune cells thereby activating both innate and adaptive immune responses. By contrast, recent studies have indicated that some tumor cells express TLRs and that TLR expression is associated with cancer risk, suggesting that TLRs may also play important roles in tumor biology.

We previously found that human tumor cell lines and tumor tissues, particularly human HCCs, express multiple TLRs (13-16). In the present study, immunohistochemical analysis
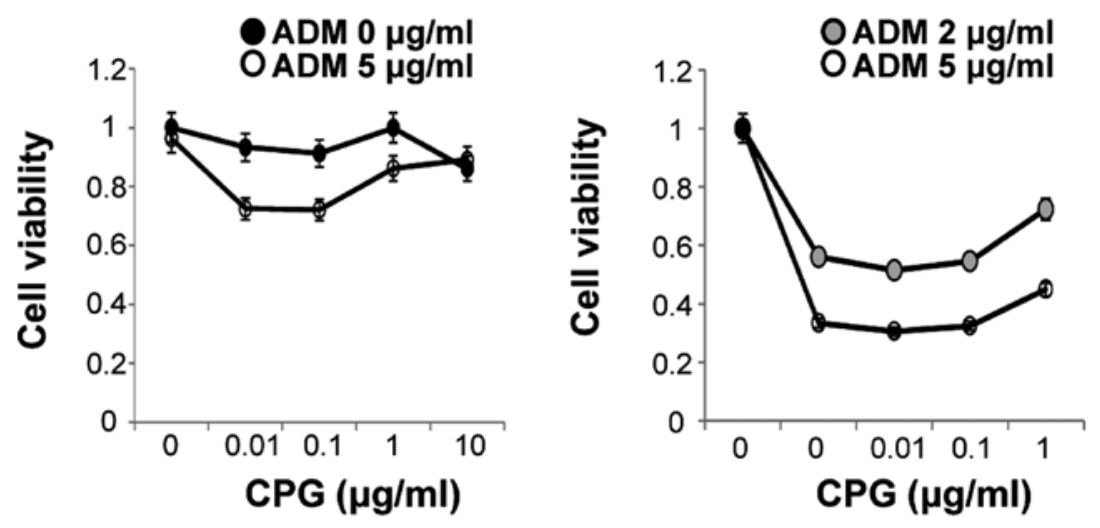

Figure 9. Effect of $\mathrm{CpG}$ in combination with an anticancer reagent on colon carcinoma cell viability. Cells of the colon carcinoma cell line Colo320 were incubated with various concentrations of $\mathrm{CpG}$ together with 0 (closed circles), 2 (dotted circles) or 5 (open circles) $\mu \mathrm{g} / \mathrm{ml}$ adriamycin (ADM), for $48 \mathrm{~h}$, following which cell viability was assessed using the MTT assay. Viability in the absence of treatment was set at 1 . Data shown are the means \pm SD of six independent experiments. 
revealed that $91.2 \%$ of colon carcinoma tissues as well as two different colon carcinoma cell lines express TLR3 in addition to its expression in non-tumor tissues such as cirrhotic or normal tissues. We previously reported the high prevalence of TLR3 in human HCC. In these previous reports, flow cytometric analysis and immune fluorescence staining indicated that TLR3 was clearly expressed both on the cell surface and in the cytoplasm of HCC cells (15). TLRs 3, 7, 8 and 9, which recognize nucleic acid ligands, are known to be expressed in the endosomes and in the endoplasmic reticulum. In the present study, a similar staining pattern of TLRs, i.e., on the cell surface and in the cytoplasm, was observed in colon carcinoma tissues as was observed in the HCCs of the previous study.

The present study indicated that stimulation of SW480 colon carcinoma cells with non-transfected Poly I:C resulted in no change in cell viability, whereas stimulation of the cells with transfected Poly I:C resulted in decreased cell viability in a dose-dependent manner. These results indicate that activation of intracellular TLR3 may predominate over that of cell surface TLR3 in this cell line.

However, the expression and function of TLR3 in cancer cells are not well understood. Although the findings of the present study indicate that cell surface stimulation of TLR3 did not affect cell viability, cell surface stimulation with Poly I:C did activate the NF- $\kappa \mathrm{B}$ signaling pathway. These results suggest that cell surface TLR3 may be functional. In cancer cells, upon activation of $\mathrm{NF}-\kappa \mathrm{B}$, the $\mathrm{NF}-\kappa \mathrm{B}$ dimers typically enter the nucleus and induce the production of cytokines, growth factors and antiapoptotic proteins. It appears that, in tumors, $\mathrm{NF}-\kappa \mathrm{B}$ can convert inflammatory stimuli into tumor cell survival and growth signals (13-16).

Stimulation of intracellular TLR3 by transfection of the cells with Poly I:C showed that transfected Poly I:C caused apoptotic cell death in colon carcinoma cells in a dose-dependent manner. These findings indicate that TLR3 signals may be linked to apoptotic signals. The combined results indicate that TLR3 signals are different depending on the localization of TLR3 i.e., whether it is on the cell surface or intracellular, and that these signals play an important role in cell survival and cell death. Similar observations have been reported for several other types of cancer cells (13-16).

Regarding TLR9, we found that TLR9 expression, similar to TLR3 expression, was prevalent in human colon carcinoma cells. There was a clear positive TLR9 signal in 86 of 100 colon carcinoma cases (86\%). TLR9 staining was detected not only in the cytoplasm, but also in the cell membrane. We previously reported that there was high expression of TLR9 in human HCC. In that previous study, western blot analysis of subcellular fractions, and flow cytometric analysis of intact cells, clearly demonstrated the expression of TLR9 on both the cell surface and in the cytoplasm of human HCC cells (16). In the present study, the staining pattern of TLR3 in colon carcinoma cells was similar to that of TLR9 in the previous study of HCCs.

We then investigated the function of TLR9 in colon carcinoma cells. We demonstrated that stimulation with CpG-ODNs increased the cell viability of SW480 cells. This result suggested that cell surface stimulation with $\mathrm{CpG-ODNs}$ might affect cell proliferation and survival in these colon carcinoma cells. This result is consistent with the fact that the enhanced cell proliferation and survival of HCC cells (16). We further found that activation of TLR9 with CpG-ODNs in both colon carcinoma cell lines upregulated NF- $\kappa \mathrm{B}$ activity. In general, engagement of the TLR9 signaling pathway leads to the activation of two major transcription factors that have central roles in innate immunity, i.e., NF- $\mathrm{B}$ and IRF-7. TLR9 requires the adaptor molecule MyD88 for initiation of these signals, and MyD88 can directly associate with and activate IRF-7, leading to type I-IFN production $(19,20)$. NF- $\kappa \mathrm{B}$ usually plays an important role in regulating immune and inflammatory responses, apoptosis and oncogenes $(21,22)$. Thus the $\mathrm{CpG}-\mathrm{ODN}$-activation of $\mathrm{NF}-\kappa \mathrm{B}$ activity is consistent with other studies of TLR9 signaling.

Finally, we found that cell surface stimulation with CpG-ODNs reduced the cytotoxicity of ADM. We previously showed that cell surface stimulation with CpG-ODNs might contribute to a reduction in the cytotoxicity of ADM towards HepG2 cells via the upregulation of apoptosis inhibitors (16). We therefore speculated that the reduction in ADM cytotoxicity in colon carcinoma cells by CpG-ODNs may be mediated by the same mechanism.

In conclusion, functional TLR3 and TLR9 are expressed in colon carcinoma cells. TLR3 and TLR9 activate NF- $\kappa \mathrm{B}$ and the activation of these TLRs is closely related to cell death and survival. Further evaluation of the possible roles and regulation of TLR3 and TLR9 are critical for controlling cell death, proliferation and immune escape of malignant cells.

\section{References}

1. Takeda K, Kaisho T and Akira S: Toll-like receptors. Annu Rev Immunol 21: 335-376, 2003.

2. Takeda $\mathrm{K}$ and Akira S: Toll-like receptors in innate immunity. Int Immunol 17: 1-14, 2005.

3. Beutler B, Jiang Z, Georgel P, Crozat K, Croker B, Rutschmann S, et al: Genetic analysis of host resistance: Toll-like receptor signaling and immunity at large. Annu Rev Immunol 24: 353-389, 2006.

4. Akira S. Uematsu S and Takeuchi O: Pathogen recognition and innate immunity. Cell 124: 783-801, 2006.

5. Bauer S, Kirschning CJ, Häcker H, Redecke V, Hausmann S, Akira S, Wagner H and Lipford GB: Human TLR9 confers responsiveness to bacterial DNA via species-specific $\mathrm{CpG}$ motif recognition. Proc Natl Acad Sci USA 98: 9237-9242, 2001.

6. Becker MN, Diamond G, Verghese MW and Randell SH: CD14-dependent lipopolysaccharide-induced beta-defensin-2 expression in human tracheobronchial epithelium. J Biol Chem 275: 29731-29736, 2000.

7. Faure E, Thomas L, Xu H, Medvedev A, Equils O and Arditi M: Bacterial lipopolysaccharide and IFN-gamma induce Toll-like receptor 2 and Toll-like receptor 4 expression in human endothelial cells: role of NF-kappa B activation. J Immunol 166: 2018-2024, 2001.

8. Barton GM, Kagan JC and Medzhitov R: Intracellular localization of Toll-like receptor 9 prevents recognition of self-DNA but facilitates access to viral DNA. Nat Immunol 7: 49-56, 2006.

9. Yamamoto M, Sato S, Hemmi H, Hoshino K, Kaisho T, Sanjo H, Takeuchi O, Sugiyama M, Okabe M, Takeda K and Akira S: Role of adaptor TRIF in the MyD88-independent toll-like receptor signaling pathway. Science 301: 640-643, 2003.

10. Alexopoulou L, Holt AC,Medzhitov R and Flavell RA: Recognition of double-stranded RNA and activation of NF-kappaB by Toll-like receptor 3. Nature 413: 732-738, 2001.

11. Khvalevsky E, Rivkin L, Rachmilewitz J, Galun E and Giladi H: TLR3 signaling in a hepatoma cell line is skewed towards apoptosis. J Cell Biochem 100: 1301-1312, 2007.

12. Huang B, Zhao J, Unkeless JC, Feng ZH and Xiong H: TLR signaling by tumor and immune cells: a double-edged sword. Oncogene 27: 218-224, 2008. 
13. Yu L and Chen S: Toll-like receptors expressed in tumor cells: targets for therapy. Cancer Immunol Immunother 57: 1271-1278, 2008.

14. Sato Y, Goto Y, Narita N and Hoon DS: Cancer cells expressing Toll-like receptors and the tumor microenvironment. Cancer Microenviron 2: 205-214, 2009.

15. Yoneda K, Sugimoto K, Shiraki K, Tanaka J, Beppu T, Fuke H Yamamoto N, Masuya M, Horie R, Uchida K and Takei Y: Dual topology of functional Toll-like receptor 3 expression in human hepatocellular carcinoma: Differential signaling mechanisms of TLR3-induced NF-kappaB activation and apoptosis. Int J Oncol 33: 929-936, 2008.

16. Tanaka J, Sugimoto K, Shiraki K, Tameda M, Kusagawa S Nojiri K, Beppu T, Yoneda K, Yamamoto N, Uchida K, Kojima T and Takei Y: Functional cell surface expression of toll-like receptor 9 promotes cell proliferation and survival in human hepatocellular carcinomas. Int J Oncol 37: 805-814, 2010.

17. Sun R, Zhang Y, Lv Q, Liu B, Jin M, Zhang W, He Q, Deng M, Liu X, Li G, Li Y, Zhou G, Xie P, Xie X, Hu J and Duan Z: Toll-like receptor 3 (TLR3) induces apoptosis via death receptors and mitochondria by up-regulating the transactivating p63 isoform alpha (TAP63alpha). J Biol Chem 286: $15918-15928,2011$
18. Salaun B, Lebecque S, Matikainen S, Rimoldi D and Romero P: Toll-like receptor 3 expressed by melanoma cells as a target for therapy? Clin Cancer Res 13: 4565-4574, 2007.

19. Honda K, Yanai H, Mizutani T, Negishi H, Shimada N Suzuki N, Ohba Y, Takaoka A, Yeh WC and Taniguchi T: Role of a transductional-transcriptional processor complex involving MyD88 and IRF-7 in Toll-like receptor signaling. Proc Natl Acad Sci USA 101: 15416-15421, 2004

20. Kawai T, Sato S, Ishii KJ, Coban C, Hemmi H, Yamamoto M, Terai K, Matsuda M, Inoue J, Uematsu S, Takeuchi O and Akira S: Interferon-alpha induction through Toll-like receptors involves a direct interaction of IRF7 with MyD88 and TRAF6. Nat Immunol 5: 1061-1068, 2004

21. Karin M, Cao Y, Greten FR and Li ZW: NF-kappaB in cancer: from innocent bystander to major culprit. Nat Rev Cancer 2: 301-310, 2002.

22. Ghosh S and Karin M: Missing pieces in the NF- $\kappa \mathrm{B}$ puzzle. Cell 109: S81-S96, 2002. 